\title{
The effect of an active video game intervention on physical activity, motor performance, and fatigue in children with cancer: a randomized controlled trial
}

\author{
Lotta Hamari ${ }^{1,2^{*}} \mathbb{C}$, Liisa S. Järvelä3 ${ }^{3}$, Päivi M. Lähteenmäki ${ }^{3}$, Mikko Arola $^{4}$, Anna Axelin ${ }^{1,2}$, Tero Vahlberg ${ }^{5}$ \\ and Sanna Salanterä ${ }^{1,2}$
}

\begin{abstract}
Objective: To evaluate the effect of active video games in promoting physical activity and motor performance, and reducing fatigue in children with cancer. A randomized controlled trial was conducted. The intervention included playing Nintendo Wii ${ }^{\mathrm{TM}}$ Fit (Nintendo Co., Ltd., Kyoto, Japan) for $30 \mathrm{~min} /$ day for 8 weeks. Physical activity was estimated with accelerometers, physical activity diaries and questionnaires. Movement-ABC2 and PedsQL ${ }^{\mathrm{TM}}$ were used to examine motor performance and fatigue. Intervention experiences and fidelity were examined with an interview.

Results: Participants ( $n=36$ children with cancer, 3-16 years-old) were randomly assigned to the intervention and control groups. The median [min-max] accelerometer counts/h (500 [131-1130] vs 385 [116-1012], $p=0.63$ ) and physical activity min/day (34 [0-150] vs 23 [0-260], $p=0.95$ ) did not differ between the groups. Change between the pre-test and post-test regarding motor performance and fatigue was similar in both groups (motor performance $p=0.77$; fatigue $p=1.00$ ). Participants experienced playing active video games meaningful, but the intervention was not followed completely as instructed. Overall, the physical activity levels were low and one fourth of the children had or were at risk of having movement difficulties.
\end{abstract}

Trial registration: ClinicalTrials.gov identifier: NCT01748058 (October 15, 2012)

Keywords: Physical activity, Motor performance, Fatigue, Active video games, Randomized controlled trial

\section{Introduction}

Children with cancer have to spend long periods at the hospital and are suggested to be less physically active than their healthy peers $[1,2]$, and lag behind in motor skill development [3]. Together with the disease and its intensive medical treatment, low levels of physical activity (PA) may lead to secondary health problems during and after cancer [4].

Increasing PA and exercise training, even during treatment, are feasible, beneficial and safe [5-8]. For better

*Correspondence: lotta.hamari@utu.fi

${ }^{1}$ Department of Nursing Science, University of Turku, 20014 Turku, Finland

Full list of author information is available at the end of the article engagement, interventions should also be fun [9], flexible to allow for individual tailoring [10], and feasible both at hospital and home. The starting point of this study was the need to activate children with cancer in a fun, entertaining and effective manner. That is how we settled upon building the intervention around active video games (AVG). Playing AVGs equals to light-to-moderate PA [11].

The aim of this study was to evaluate the effect of AVGs with regard to the promotion of PA and motor performance, and reducing fatigue in children with cancer. The detailed protocol of the study is reported by Kauhanen et al. [12]. 


\section{Main text Methods}

The study was conducted as a randomized controlled trial. Sample size was calculated based on PA measured in accelerometer counts. Mean accelerometer counts at baseline and standard deviation for both groups were set based on the study by Winter et al. [1]. The required sample size was 34 participants $(80 \%$ power with a $5 \%$ significance level). The eligibility criteria for participants were (1) 3-16 years of age at the time of the diagnosis of acute lymphoblastic leukaemia or other cancer outside the central nervous system, (2) treatment included vincristine, and (3) the children were treated in either of the designated hospitals. Participant flow is reported in Fig. 1.

Physical activity was estimated with accelerometers, activity diaries, and two questionnaires. We used Fitbit Ultra (Fitbit Inc., San Francisco, USA) accelerometers. Fitbits were worn on the waist when being awake during the first week of the intervention. The minimum requirement for daily wear time was $8 \mathrm{~h}$. The follow-up measurement was at 1 year. The results are reported as mean activity counts/h (Additional file 1).

Participants filled out activity diary in 10-min periods, for the first week of the intervention. The results are reported as the mean time/day spent on PAs called as "physical activity min/day". The activity diaries were also used when evaluating the intervention fidelity by calculating how many minutes participants played AVGs. This is reported as "AVG playing min/week" in Table 2.

The metabolic equivalent (MET) questionnaire [13] assessed leisure-time PA in MET h/week pre-test and post-test. The MET questionnaire contained 3 multiple-choice questions about PA intensity, duration, and frequency.

Motor performance was estimated using the Movement Assessment Battery for Children-2 (M-ABC2) test [14, 15] pre-test and post-test. The scores are reported in percentiles and the higher score indicates better performance.

Fatigue was estimated with $\operatorname{Peds} Q L^{\mathrm{TM}}$ Multidimensional Fatigue Scale questionnaire proxy reports [16]. The scores are reported on a scale from 0 to 100 . The higher scores indicate lower problems.

Parents filled in the activity diary and questionnaires as a proxy reports of their child for the children below 10 years of age.

Experiences and fidelity of the intervention were examined with an interview. Each child was interviewed after the intervention. The children in the intervention group were asked about their experiences of the intervention and AVGs in order to know how well the intervention was followed. The interview included also a question about PA barriers in the hospital.
Acceptability of the intervention was evaluated based on Bowen et al. [17] and similarly than Nielsen et al. [18] by reporting the participation rate from the eligible patients and by reporting the retention rate of the participants during follow-up. We also gained information about the acceptability from the interviews.

The baseline characteristics were collected from the electronic patient records.

The intervention was managed by a physical therapist at the hospital ward and via telephone. The intervention included the use of elective Nintendo WiiFit ${ }^{\mathrm{TM}}$ games for at least $30 \mathrm{~min} /$ day for 8 weeks, both during hospitalization and at home. The intervention included face-to-face and written information, recommendations for PA, and the education required to use the games with age-specific instructions. In addition, the intervention group received a motivational phone call in the middle of the intervention. The control group received general written advice for PA of $30 \mathrm{~min} /$ day.

The first intervention meeting or the control intervention meeting were at a mean (SD) of 15.4 (13.3) days from the initial diagnosis.

The differences in the changes in scores between groups were compared with Mann-Whitney U-test. Non-parametric tests were used due to the skewed distribution of the outcome variables. The statistical computations were performed with SPSS Statistics for Windows 23 (IBM Corp., Armonk, NY). If $p$-values were less than 0.05 they were considered statistically significant. The interview data were analysed using qualitative content analysis.

\section{Results}

The final sample size was $36 / 47$ eligible participants (10 girls; 26 boys, participation rate $77 \%$ ). The baseline characteristics of the study participants are reported in Table 1.

\section{Physical activity}

The difference between median (min-max) accelerometer counts for the intervention group $(n=12) 500$ counts/h (131-1130) and control group $(n=18) 385$ counts/h (116-1012) during the first week of the intervention was not significant $(p=0.63)$. Similarly, the difference between median of PA min/day, counted from the PA diary for the intervention group $(n=12) 34 \mathrm{~min} /$ day $(0-150)$ and for the control group $(n=16) 23 \mathrm{~min} /$ day $(0-260)$ was not significant $(p=0.95)$. The change in accelerometer counts between the first and the follow-up measurement did not differ between the groups $(p=0.22)$ (Table 2).

The median (min-max) MET h/week pre-test scores for the intervention group were $20(3-55)$ and for the 


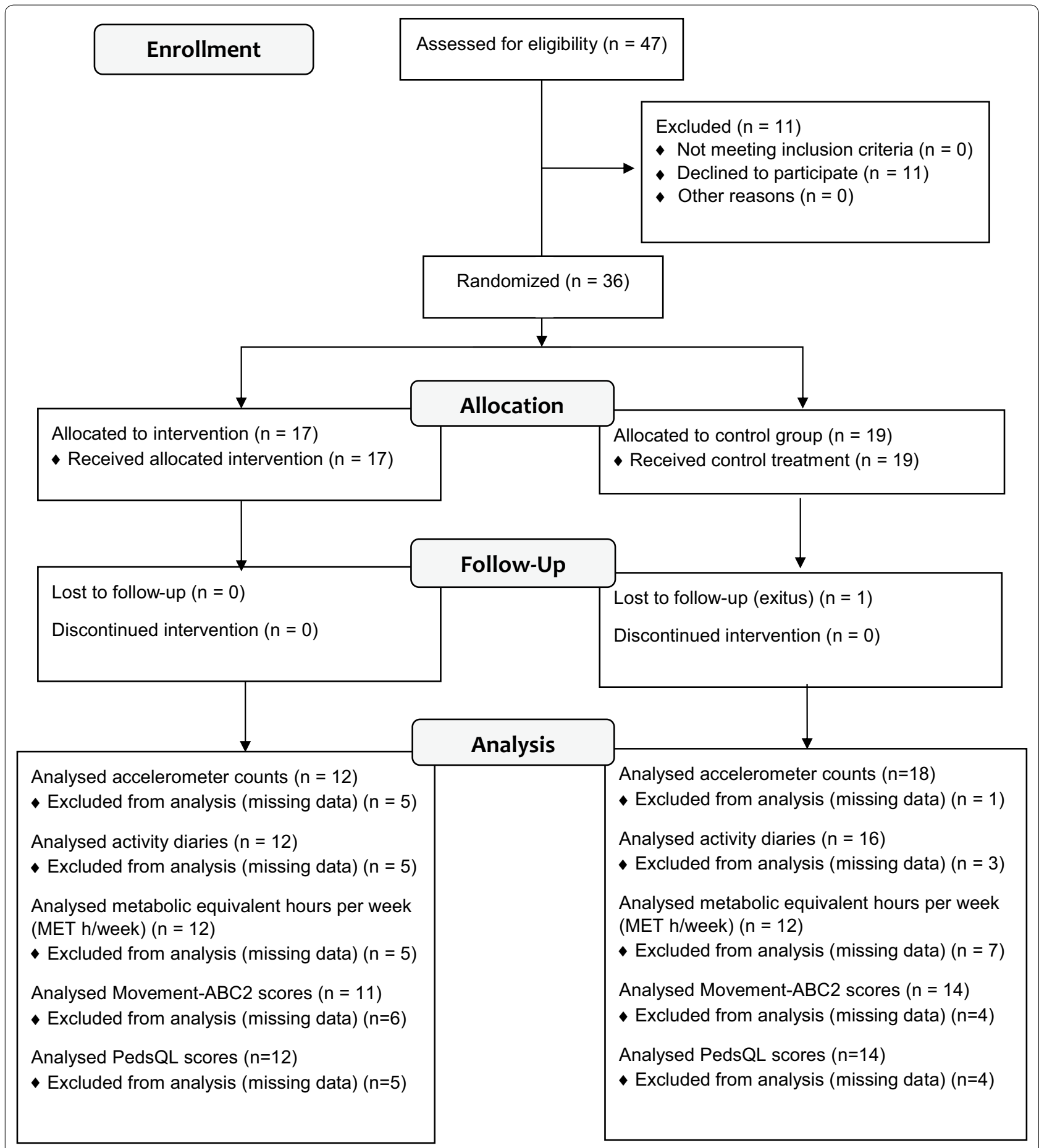

Fig. 1 Participant flow

control group 22 (7-92). The median MET h/week posttest scores were $16(2-52)$ for the intervention group and 21 (1-92) for the control group. The change in MET $\mathrm{h} /$ week did not differ between the groups $(p=0.38)$ (Table 2).

\section{Motor performance}

The median $(\min -\max ) \mathrm{M}-\mathrm{ABC} 2$ pre-test score in the intervention group was 75 (5-99) and post-test 63 (0-95). Median (min-max) M-ABC2 pre-test score for control group was 50 (0-99) and post-test 37 (1-98). At 
Table 1 The baseline characteristics of the study participants

\begin{tabular}{|c|c|c|c|}
\hline & Study cohort $(n=36)$ & Intervention group $(n=17)$ & $\begin{array}{l}\text { Control } \\
\text { group } \\
(n=19)\end{array}$ \\
\hline \multicolumn{4}{|l|}{ Age at recruitment (years) } \\
\hline Mean (min-max) & $7.8(3-16)$ & $7.8(3-16)$ & $7.9(3-15)$ \\
\hline Gender (N, female:male) & $10: 26$ & $5: 12$ & $5: 14$ \\
\hline \multicolumn{4}{|l|}{ Diagnose } \\
\hline Acute lymphocytic leukemia (SR:IR:HR) & $17(8: 6: 3)$ & $7(4: 2: 1)$ & $10(4: 4: 2)$ \\
\hline Wilms'tumor & 2 & 2 & 0 \\
\hline Burkitt lymphoma & 3 & 1 & 2 \\
\hline Non-Hodgkin lymphoma & 5 & 3 & 2 \\
\hline Hodgkin lymphoma & 3 & 1 & 2 \\
\hline Other neoplasm & 6 & 3 & 3 \\
\hline \multicolumn{4}{|c|}{ Vincristine/vinblastine during first 3 months from diagnose (mg/sqm) } \\
\hline Mean (STD) & $10.2(4.2)$ & $10.2(4.0)$ & $10.1(4.4)$ \\
\hline Min-Max & $1.4-17.5$ & $3.3-16.2$ & $1.4-17.5$ \\
\hline \multicolumn{4}{|c|}{ Physical therapy (visits during the intervention period) } \\
\hline Mean (STD) & $3(2.2)$ & $2.4(1.6)$ & $3.6(2.6)$ \\
\hline Min-Max & $0-9$ & $1-7$ & $0-9$ \\
\hline \multicolumn{4}{|c|}{ Days admitted (during the intervention period) } \\
\hline Mean (STD) & $32.7(13.6)$ & $30.5(12.1)$ & $34.7(14.8)$ \\
\hline Min-Max & $10-59$ & $12-59$ & $10-57$ \\
\hline \multicolumn{4}{|c|}{ Hospital visits (during the intervention period) } \\
\hline Mean (STD) & $11.2(7.2)$ & $12.5(7.4)$ & $10.1(7.1)$ \\
\hline Min-Max & $1-35$ & $4-35$ & $1-26$ \\
\hline
\end{tabular}

$S R$ standard risk, IR intermediate risk, $H R$ high risk

Table 2 Descriptive values of the outcome measures

\begin{tabular}{|c|c|c|c|c|c|}
\hline & \multicolumn{2}{|c|}{ Intervention group } & \multicolumn{2}{|c|}{ Control group } & \multirow[t]{2}{*}{$p$-value } \\
\hline & $\mathbf{N}$ & Median (min-max) & $\mathbf{N}$ & Median (min-max) & \\
\hline \multicolumn{6}{|l|}{ Accelerometer counts/h } \\
\hline During the intervention & 12 & 500 (131 to 130$)$ & 18 & 385 (116 to 1012) & 0.63 \\
\hline At 1 year & 10 & 524 (284 to 1381) & 12 & 928 (462 to 1384) & 0.05 \\
\hline Change $^{a}$ & 9 & 212 ( -324 to 1064$)$ & 12 & $410(-20$ to 1087$)$ & 0.22 \\
\hline Active video game playing min/week & 12 & $30(0$ to 280$)$ & 15 & 0 (0 to 300$)$ & 0.18 \\
\hline Physical activity min/day & 12 & 34 (0 to 150) & 16 & 23 (0 to 260) & 0.95 \\
\hline \multicolumn{6}{|l|}{ Metabolic equivalents h/week } \\
\hline At baseline & 13 & 20 (3 to 55$)$ & 16 & 22 (7 to 92 ) & \\
\hline After the intervention & 8 & 16 (2 to 52$)$ & 12 & 21 (1 to 92) & \\
\hline Change $^{\mathrm{a}}$ & 12 & $-0.34(-52$ to 33$)$ & 12 & $0(-34$ to 15$)$ & 0.38 \\
\hline \multicolumn{6}{|l|}{ Movement-ABC-2 (percentile) } \\
\hline At baseline & 13 & 75 (5 to 99) & 16 & 50 (0 to 99) & \\
\hline After the intervention & 14 & 63 (0 to 95) & 17 & $37(1$ to 98$)$ & \\
\hline Change $^{\mathrm{a}}$ & 11 & $-4(-47$ to 54$)$ & 14 & 0 (-83 to 45$)$ & 0.77 \\
\hline \multicolumn{6}{|l|}{ PedsQL Fatigue scores } \\
\hline At baseline & 14 & 67 (35 to 100) & 17 & 60 (39 to 97) & \\
\hline After the intervention & 12 & 67 (40 to 92) & 14 & 66 (47 to 90) & \\
\hline Change $^{\mathrm{a}}$ & 12 & $4(-35$ to 68$)$ & 14 & $6(-7$ to 64$)$ & 1.00 \\
\hline
\end{tabular}

a Only participants with data at both measurement points were included in the analysis 
pre-test, $8 \%$ of the intervention group and $31 \%$ of the control group, and at post-test $21 \%$ of the intervention group and $29 \%$ of the control group had or were at risk of having movement difficulties. The change in $\mathrm{M}-\mathrm{ABC} 2$ scores between the pre- and post-tests did not differ between the groups $(p=0.77)$ (Table 2$)$.

\section{Fatigue}

The median (min-max) fatigue pre-test scores in the intervention group were 67 (35-100) vs 60 (39-97) in the control group. Post-test fatigue score were 67 (40-92) in the intervention group vs 66 (47-90) in the control group. The change in fatigue scores between the pre- and post-tests did not differ between the groups $(p=1.00)$ (Table 2).

\section{Intervention experiences}

Based on the interviews, most of the participants experienced playing AVGs to be meaningful and enjoyable. However, some guardians of the youngest children (3 years old) reported that the games were too difficult, and the child lost focus when playing. One guardian told that they did not install the games at home as there was too much going on at the beginning of the treatment. One child told getting bored to the games due to playing them so much. One child would have wanted to continue playing even after the intervention, since enjoyed it so much with friends and family. The most positive experiences about the games were reported by primary schoolaged children and their guardians. The games were liked specifically when participants were instructed to stay in their own patient room and they felt not having many other possibilities to be active.

Barriers for physical activity during the hospital stays were infusion cannula (lack of ideas how to be active with it), fatigue and lack of space (too little patient rooms and lack of play/exercise area). Being stuck in the patient room or with the infusion lines, were lowering mood which in turn lessened their activity. Participants wished for gym or exercise area (including soccer goals, basketball hoops, pedal cars and tractors) on the ward. Older children told they miss organized PA for children with cancer since they could not take part to their own hobbies which they missed a lot.

\section{Intervention fidelity}

Based on the PA diaries 6/12 children in the intervention group and $3 / 15$ children in the control group had played AVGs during the first week of the intervention. Only one participant in the intervention group reported that he/she had played as instructed $(30 \mathrm{~min} /$ day $=210 \mathrm{~min} /$ week). The AVG minutes (median) per week per group are reported in the Table 2 . Based on the PA diaries and the interviews, the intervention was not followed as recommended.

\section{Acceptability of the intervention}

Based on the participation rate (77\%), the intervention was accepted relatively well. Even though we had missing data, no-one of the 36 participants self-wanted to withdraw from the study during the 2.5 year follow-up. Participants in the intervention group were satisfied to get the possibility to play AVGs even though they did not use them in the end as instructed.

\section{Discussion}

In the present study, we did not find differences between the intervention and control group in PA, motor performance, or fatigue. However, the intervention was not successfully followed, and therefore definite conclusions about the intervention effects cannot be made. The intervention was well accepted based on the study participation and retention rate and mostly enjoyed based on the interviews. Adverse effects were not reported. Our results are partly in discrepancy and partly in line with the earlier findings $[19,20]$. Active video gaming has been suggested to improve body coordination in survivors of childhood brain tumors [19] and to be feasible as a part of home-based exercise program in paediatric patients after hematopoietic stem cell transplantation [20].

Our intervention was likely to be too early, at least without supervision and personalized guidance, which might be one reason for poor fidelity. Nonetheless, recent evidence is reasoning early PA interventions since Nielsen et al. found $24 \%$ reduction at 3 months in physical function in children with ALL [18]. Motivating children to be physically active from the beginning of the treatment with the existing resources remains a challenge. Every-day personalized guidance to PA might not be possible in many hospitals, and therefore also independently performed daily activity is important to be promoted. Families might need psychosocial support for $\mathrm{PA}$, and education regarding the benefits of PA during the cancer treatment [8].

As a clinical perspective, AVGs can be feasible addition to traditional therapies and can bring variation to exercise programs which is extremely important in engaging children in PA. Games should be further developed also in mobile devices in order to offer interventions that are attractive, up-to-date, and effective. Digital solutions are, after all, an integral part of the children's lives today. Further research of AVGs during cancer treatment is encouraged to verify the results. 


\section{Limitations}

Limitations of the study include poor fidelity of the intervention and problems with data collection. Missing questionnaires and problems with the accelerometer data (devices got lost or the data was erroneous) resulted to data loss. At present, we also acknowledge that the data collection period with the accelerometer and activity diaries were too short to gain precise information about the main outcome and the intervention fidelity.

The common challenges with eHealth interventions, the rapid development speed of technology and relatively slow speed of implementing research, were present in our study. When the study protocol was ready and the implementation of the study began, the game console that we used was replaced with a newer one by the manufacturer. Also, those Fitbit accelerometers that we used in our data collection are no longer in production. Despite these challenges, the results and lessons learned from our study may be used in similar studies and in justifying the efforts in PA promotion in children with cancer.

\section{Supplementary information}

Supplementary information accompanies this paper at https://doi. org/10.1186/s13104-019-4821-z.

Additional file 1: Figure S1. Individual changes for physical activity (Fitbit step counts) during the intervention and at follow-up measurement at 12 months.

\section{Abbreviations}

PA: physical activity; AVG: active video games; M-ABC2: Movement Assessment Battery for Children-2; MET: the metabolic equivalent.

\section{Acknowledgements}

We gratefully thank all study participants and their families for taking part in this study. The assistance of the research nurses and physiotherapists in both designated hospitals and the staff of both of the study wards in Turku University Hospital and Tampere University Hospital are gratefully acknowledged.

\section{Authors' contributions}

LH, LSJ, PML, MA, AA, TV and SS participated in the design of the study. The original manuscript was drafted by $\mathrm{LH}$ and reviewed and commented by all authors LH, LSJ, PML, MA, AA, TV and SS. LH and TV conducted the statistical analyses. All authors read and approved the final manuscript.

\section{Funding}

The study was funded by the Cancer Society of South-West Finland, TYKS Foundation, and Finnish Association of Physiotherapists. The primary investigator held an UTUGS-funded (University of Turku Graduate School-funded) doctoral training position. The funders had no role in the design of the study, in the data collection, analysis, the interpretation of data or writing the manuscript.

\section{Availability of data and materials}

The datasets used and analysed during the current study are available from the corresponding author $(\mathrm{LH})$ on reasonable request.

\section{Ethics approval and consent to participate}

The study was approved by the Joint Commission on Ethics of Hospital district of South-West Finland (15.5.2012 § 153), and the research approvals were obtained from both participating institutions (24.9.2012 K66/12 No. 13059 and 21.3.2013 65 \&13030). Research was performed in accordance with the Declaration of Helsinki. All study participants over 6 years of age and their guardians signed a written informed consent. Younger participants gave oral acceptance of their participation and their guardians a written informed consent. Participants could withdraw at any time without the need to justify their decision [21].

\section{Consent for publication}

Not applicable.

\section{Competing interests}

The authors declare that they have no competing interests.

\section{Author details}

${ }^{1}$ Department of Nursing Science, University of Turku, 20014 Turku, Finland. ${ }^{2}$ Turku University Hospital, PL 52, 20521 Turku, Finland. ${ }^{3}$ Department of Pediatric and Adolescent Medicine, Turku University Hospital, PL 52, 20521 Turku, Finland. ${ }^{4}$ Department of Pediatrics, Tampere University Hospital, PL 2000, 33521 Tampere, Finland. ${ }^{5}$ Department of Biostatistics, University of Turku, 20014 Turku, Finland.

Received: 30 April 2019 Accepted: 22 November 2019

Published online: 29 November 2019

\section{References}

1. Winter C, Muller C, Brandes M, Brinkmann A, Hoffmann C, Hardes J, et al. Level of activity in children undergoing cancer treatment. Pediatr Blood Cancer. 2009;53(3):438-43.

2. Winter C, Muller C, Hoffmann C, Boos J, Rosenbaum D. Physical activity and childhood cancer. Pediatr Blood Cancer. 2010;54(4):501-10.

3. Green JL, Knight SJ, McCarthy M, De Luca CR. Motor functioning during and following treatment with chemotherapy for pediatric acute lymphoblastic leukemia. Pediatr Blood Cancer. 2013;60(8):1261-6.

4. Diller L, Chow EJ, Gurney JG, Hudson MM, Kadin-Lottick NS, Kawashima $\mathrm{Tl}$, et al. Chronic disease in the childhood cancer survivor study cohort: a review of published findings. J Clin Oncol. 2009;27(14):2339-55.

5. Braam Kl, van der Torre P, Takken T, Veening MA, van Dulmen-den Broeder E, Kaspers GJ. Physical exercise training interventions for children and young adults during and after treatment for childhood cancer. Cochrane Database Syst Rev. 2013;4:CD008796.

6. Mizrahi D, Wakefield CE, Fardell JE, Quinn VF, Lim Q, Clifford BK, et al. Distance-delivered physical activity interventions for childhood cancer survivors: a systematic review and meta-analysis. Crit Rev Oncol Hematol. 2017;118:27-41.

7. Rustler V, Hagerty M, Daeggelmann J, Marjerrison S, Bloch W, Baumann FT. Exercise interventions for patients with pediatric cancer during inpatient acute care: a systematic review of literature. Pediatr Blood Cancer. 2017;64(11):e26567. https://doi.org/10.1002/pbc.26567.

8. San Juan AF, Wolin K, Lucia A. Physical activity and pediatric cancer survivorship. Recent Results Cancer Res. 2011;186:319-47.

9. Martins J, Marques A, Sarmento H, Carreiro Costa F. Adolescents' perspectives on the barriers and facilitators of physical activity: a systematic review of qualitative studies. Health Educ Res. 2015;30(5):742-55.

10. Gotte M, Kesting SV, Winter CC, Rosenbaum D, Boos J. Motor performance in children and adolescents with cancer at the end of acute treatment phase. Eur J Pediatr. 2015;174(6):791-9.

11. Ainsworth BE, Haskell WL, Herrmann SD, Meckes N, Bassett DR Jr, TudorLocke C, et al. 2011 Compendium of physical activities: a second update of codes and MET values. Med Sci Sports Exerc. 2011;43(8):1575-81.

12. Kauhanen $L$, Jarvela $L$, Lahteenmaki PM, Arola M, Heinonen OJ, Axelin A, et al. Active video games to promote physical activity in children with cancer: a randomized clinical trial with follow-up. BMC Pediatr. 2014;5(14):94.

13. Raitakari OT, Taimela S, Porkka KV, Leino M, Telama R, Dahl M, et al. Patterns of intense physical activity among 15- to 30-year old Finns. The cardiovascular risk in Young Finns study. Scand J Med Sci Sports. 1996;6(1):36-9. 
14. Henderson SE, Sugden DA. The movement assessment battery for children: manual. London: Psychological Corporation; 1992.

15. Henderson SE, Sugden DA, Barnett AL. Movement assessment battery for children. Examiner's manual, vol. 2. London : Harcourt Assessment; 2007.

16. Varni JW, Burwinkle TM, Katz ER, Meeske K, Dickinson P. The PedsQL in pediatric cancer: reliability and validity of the pediatric quality of life inventory generic core scales, multidimensional fatigue scale, and cancer module. Cancer. 2002;94(7):2090-106.

17. Bowen DJ, Kreuter M, Spring B, Cofta-Woerpel L, Linnan L, Weiner D, et al. How we design feasibility studies. Am J Prev Med. 2009;36(5):452-7.

18. Nielsen MKF, Christensen JF, Frandsen TL, Thorsteinsson T, Andersen LB, Christensen $\mathrm{KB}$, et al. Testing physical function in children undergoing intense cancer treatment-a RESPECT feasibility study. Pediatr Blood Cancer. 2018;65(8):e27100

19. Sabel M, Sjolund A, Broeren J, Arvidsson D, Saury JM, Blomgren K, et al. Active video gaming improves body coordination in survivors of childhood brain tumours. Disabil Rehabil. 2016;38(21):2073-84.
20. Chamorro-Viña C, Valentín J, Fernández L, González-Vicent M, Pérez-Ruiz M, Lucía A, et al. Influence of a moderate-intensity exercise program on early NK cell immune recovery in pediatric patients after reducedintensity hematopoietic stem cell transplantation. Integr Cancer Ther. 2017;16(4):464-72.

21. Ministry of Justice. Finland FINLEX ${ }^{\circledR}$ 9.4.1999/488 Medical Research Act 9.4.1999/488. Finland: Edita Publishing Oy; 2010.

\section{Publisher's Note}

Springer Nature remains neutral with regard to jurisdictional claims in published maps and institutional affiliations.
Ready to submit your research? Choose BMC and benefit from:

- fast, convenient online submission

- thorough peer review by experienced researchers in your field

- rapid publication on acceptance

- support for research data, including large and complex data types

- gold Open Access which fosters wider collaboration and increased citations

- maximum visibility for your research: over 100M website views per year

At BMC, research is always in progress.

Learn more biomedcentral.com/submissions 